\title{
A conjugação do verbo odiar em $O$ matador, de Patrícia Melo
}

Sandra Souza ${ }^{1}$

Resumo: Este artigo tem como objetivo, através da análise de $O$ Matador de Patrícia Melo, problematizar o já antigo debate sobre o papel da ética na crítica literária. Fazendo parte de uma nova geração de escritores brasileiros, Patrícia Melo traz para a sua obra literária questões que desestabilizam visões dicotômicas sobre a vida e o humano, reacendendo a chama da problemática do papel da literatura e da arte na sociedade contemporânea.

Palavras-chave: Ética. Vida. Arte. Literatura. Dicotomia.

E decerto a melhor maneira de fazer entrar um cidadão na ordem - é fazê-lo entrar no cemitério.

Eça de Queirós, Farpas

People care for the books they read; and they are changed by what they care for - both during the time of reading and in countless later ways more difficult to discern.

Martha C. Nussbaum

\section{Introdução}

A segunda citação que abre este ensaio se encontra em um artigo de Martha Nussbaum, intitulado "Reading for life", em que a autora discute o papel das humanidades e da interpretação de textos na nossa cultura. Mais detalhadamente, Nussbaum elabora uma recensão apurada do argumento de Wayne Booth, em The company we keep, que recai sobre a polêmica criada em relação à questão da dialéctica entre arte e vida, ou seja, sobre a insurgência contra a crítica literária que visa à ética. Na essência, o que Booth e Nussbaum defendem não é mais do que a necessidade de termos em conta nossas relações com obras literárias como elementos importantes na construção do carácter pessoal, que o discurso crítico-ético sobre essas relações não é apenas legítimo, mas sim essencial na formação de sociedades justas e racionais. ${ }^{2}$

\footnotetext{
${ }^{1}$ Mestre em Estudos Portugueses pela University of Massachusetts Dartmouth e em Estudos Portugueses e Brasileiros pela Brown University. Encontra-se na fase de conclusão do doutorado sob a orientação da Professora Leonor Simas-Almeida, da Brown University. É Visiting Instructor na University of Iowa. Tem ensaios e recensões publicados, nos EUA e no Brasil, sobre Fernando Pessoa, Bernardo Carvalho, João Ubaldo Ribeiro, António Lobo Antunes, Eça de Queirós e José Luís Peixoto. E-mail: sandra-sousa@uiowa.edu.

${ }^{2}$ Para Booth, os encontros entre o autor e o leitor são éticos na medida em que fazem ressaltar o carácter de ambos. As boas e más qualidades de carácter descrevem tanto o autor como o leitor que lhe "faz companhia".
} 
Criticar eticamente não significa, por conseguinte, ser dogmático. A ação ética só é virtuosa se for livre e só será livre se for autônoma, isto é, se resultar de uma decisão interior ao próprio agente e não vier da obediência a uma ordem, a um comando ou a uma pressão externos. Por outras palavras, a ação só é ética se realizar a natureza racional, livre e responsável do agente e se o agente respeitar a racionalidade, liberdade e responsabilidade dos outros agentes, uma vez que a subjetividade ética é uma intersubjectividade. No entanto, conforme a autora, "there are some things against which ethical criticism can perfectly reasonably take its stand. We can stand against sadism, racism, sexism" (NUSSBAUM, 1990, p. 233). Booth e Nussbaum fazem a defesa da literatura como uma forma de proporcionar uma vida mais rica e preenchida. A experiência de leitura, por conseguinte, provoca uma transformação no leitor, não apenas no ato de leitura em si, mas em momentos subsequentes. De acordo com Paul Ricoeur, o leitor aprende, através das narrativas, lições de vida cuja absorção não seria possível através de outras vias, como a filosofia, por exemplo (RICOEUR, 1986, p. 123).

$\mathrm{Na}$ atual organização da sociedade, as normas e leis são cada vez mais desenvolvidas e elaboradas, necessitando dos valores éticos para fazer sentido. No entanto, a ética parece estar cada vez mais longe e a violência é um retrato do esvaziamento de sentido do indivíduo. Ética e violência são opostas. Elas opõem-se por se tratar de seres racionais e sensíveis, dotados de linguagem e de liberdade, como se fossem coisas, isto é, irracionais, insensíveis, mudos e inertes ou passivos. Ambas estão no nosso dia-a-dia, porém a violência, a todo o momento nos faz rever pressupostos éticos, ou seja, recriando-a para justificar sua finalidade violenta.

O romance $O$ matador, de Patrícia Melo, é um exemplo que me parece flagrante da relação entre vida e arte, entre ética e violência. Através da história de Máiquel, podemos observar a complexidade do sujeito humano e a incoerência da teia social. $O$ narrador/personagem principal leva-nos a reflectir sobre a condição humana e a colocarmonos em situações-limite, situações estas que nos mostram que nem tudo é preto ou branco, que o interior do ser humano é mais cinzento do que se possa pensar. Assim sendo, e dependendo de certas condições (ou realidades) externas, as suas acções nem sempre podem ser categorizadas em caixas com etiquetas bem definidas. Apesar da sua condição de ser racional, o homem tende instintivamente para o maniqueísmo, ou seja, a divisão do mundo entre bom e

Para além do prazer estético que possam proporcionar, as narrativas interpretam sempre a vida; elas dizem-nos sobre as nossas e outras vidas possíveis. Somos atravessados por nossas leituras. 
mau, baseando as suas escolhas num dois pólos opostos. No entanto, o texto de Patrícia Melo nos leva a colocar questões fundamentais que põem em causa uma visão binária e demarcada do sujeito e das suas ações: podemos condenar a violência quando ela se apresenta na forma de sobrevivência?; É menos criminoso aquele que manda matar do que o que mata?; Onde se situam os limites da ética?; Qual o papel de certas estruturas, como a polícia, na sociedade?; Quais os critérios para definir a "normalidade" do ser humano? E a lista poderia continuar. Ao proceder-se a uma análise mais detalhada da narrativa, pretende-se demonstrar como $O$ matador surge como um texto destabilizador das noções de ética, de moralidade, de crítica literária na sua relação com o mundo da vida, obrigando o leitor a refazer algumas ideias e a confrontar-se consigo mesmo e com o outro.

\section{Eu odeio}

Aristóteles, um dos maiores pensadores ocidentais, considerava que toda a história bem contada nos ensina alguma coisa, indo ainda mais longe ao afirmar que as histórias revelam aspectos universais da condição humana. Paul Ricoeur, em um ensaio em que analisa a relação entre história e vida, afirma o seguinte:

[...] fiction, particularly narrative fiction, is an irreducible dimension of the understanding of the self. If it is true that fiction cannot be completed other than in life, and that life can not be understood other than through stories we tell about, then we are led to say that a life examined is a life narrated (RICOEUR, 1986, p. 130).

Parece-me particularmente interessante pensar neste romance de Patrícia Melo como a narração de uma vida. Faço esta afirmação, em primeiro lugar, por o romance se configurar no uso, embora não sistemático, mas quase, de um narrador de primeira pessoa, o que poderá provocar no leitor uma adesão semelhante à exercida pelo tipo autobiográfico. Neste sentido, este tipo de narrador provoca no leitor uma sensação de contiguidade entre vida e ficção, uma vez que narrador transmite uma experiência que lhe é própria. A subjectividade do narrador aqui presente opõe-se a narradores de terceira pessoa, omniscientes, cuja presença muitas das vezes nem é sentida. Assim sendo, o narrador de $O$ matador leva o leitor a compartilhar dos fatos por si narrados e sentidos.

No entanto, não é apenas o uso dessa primeira pessoa narrativa que me leva a considerar esta abordagem, mas a própria "vida" que aqui nos é contada. É a actualidade, ou 
se quisermos, contemporaneidade da história de Máiquel, que provoca no leitor essa necessidade de estender a ficção à vida. Ainda fazendo uso das palavras de Ricoeur, "a life is no more than a biological phenomenon as long o it is not interpreted. And in the interpretation fiction plays a considerable, mediating role” (RICOEUR, 1986, p. 127). Patrícia Melo, neste romance, não faz mais do que interpretar a dura realidade das vidas periféricas trazendo-as para o campo da ficção, representadas no narrador/personagem principal Máiquel.

Ao acompanharmos Máiquel em suas "aventuras" deparamo-nos com um mundo centrado na violência, na problemática da droga, do machismo, do racismo e das diferenças abismais entre classes sociais. O narrador surge-nos como "alguém" que se tornou aquele sujeito, não por escolha ou opção, mas por contingência social. O fetiche de Máiquel por seus sapatos é simbólico da sua marginalização social (o aspecto exterior é um indicativo do lugar que se ocupa numa sociedade):

Enquanto caminhava e olhava para os meus sapatos fodidos, eu pensava que a vida é uma coisa engraçada. Ela vai sozinha, como um rio, se você deixar. Você também pode botar um cabresto, fazer da vida o seu cavalo. A gente faz da vida o que quer. Cada um escolhe a sua sina, cavalo ou rio (MELO, 1995, p. 71).

Máiquel escolhe matar para ascender socialmente (o que lhe permitirá comprar sapatos novos), para mudar sua condição de vida, no entanto, essa escolha não apresenta saída, ou seja, não lhe permite ser mais do que um objeto manipulado pelos representantes do poder econômico e político. Já no final da trama, ele percebe o funcionamento da teia social que prende cada sujeito a um lugar pré-determinado:

De repente, eu tinha entendido tudo, aquela história, o lado de cá e o lado de lá... Eu era o revólver desses caras. A paz. Eles têm que ter um revólver porque todo o mundo quer roubar o videolaser deles... Agora que a merda estava fedendo, eles estavam querendo jogar o revólver no rio, queriam acabar com as provas (MELO, 1995, p. 211-12).

O narrador deixa-se levar de situação em situação, ou de crime em crime, quase como um autômato e, quando se apercebe, está inserido num emaranhado cujo fio da meada não encontra mais. A violência torna-se uma espécie de "convívio" quotidiano que liga os homens naquilo que se torna uma ambígua rede de relações. Ariel Dorfman aponta para esta situação ao afirmar que "como el hombre americano ha enfrentado el problema de su muerte y su 
libertad, y como, derrotado o vencedor, ha sabido buscar en la violencia su ser más íntimo, su vínculo ambiguo o inmediato com los demás” (DORFMAN, 1970, p. 9).

Se, no entanto, atentarmos à distinção de Benilton Bezerra Júnior, entre violência e crueldade, podemos tentar uma interpretação dos atos de Máiquel:

\begin{abstract}
A violência visa sempre a um objectivo. Ela é um meio para alcançar um fim. Podem-se discutir a legitimidade do meio, a adequação dos fins, mas a ideia de que a violência tem um alvo a distingue da crueldade, na medida em que esta parece bastar-se a si própria, abandona qualquer fim. Ela expressa em terminologia freudiana, a capacidade que têm os seres humanos de gozar com a dor física ou moral de um outro (MELO, 1995, p. 51).
\end{abstract}

Observado nesta perspectiva Máiquel se apresenta como um personagem violento e, igualmente, cruel. Por um lado, ele opera com vista a um fim, o de ter uma vida socialmente mais agradável ou estável: “[...] as o que me interessava mesmo era ficar olhando a casa do dr. Carvalho. Gostava de cruzar as pernas e pensar que ela era minha, que eu vivia ali com Erica, que eu era dentista, oi, amor, como foi seu dia?" (MELO, 1995, p. 113). Por outro lado, o narrador sente prazer com a dor do outro: "Dava gosto ver o dr. Carvalho, pelado, mancando, barrigudo, se cagando de medo, dava gosto de ver. Apontei e acertei bem no meio daquela barriga cheia de merda" (MELO, 1995, p. 217).

Com o personagem Máiquel, Patrícia explora o lado mais obscuro da condição humana que, contudo, é inerente a qualquer ser. O leitor poderá considerar as acções do narrador negativas e antiéticas, mas conhecendo as suas causas e circunstâncias, não será capaz de julgá-lo ou condená-lo:

Eles me humilharam e eu disse, vocês são legais. Eles me fizeram ter vergonha de ser o que era, de ter vindo de onde vim, de ter o que eu tinha, e eu disse, vocês são legais. Eles me desprezaram. Eles me rebaixaram, e eu achei aquilo certo, achei aquilo correcto (MELO, 1995, p. 97-8).

O hibridismo interior de Máiquel - assinalado metonimicamente pela mudança de cor de cabelo - em que o amor se confunde com ódio e vice-versa, simboliza complexidades emotivas e debates universais dentro do ser humano. Máiquel é um personagem que vive em um mundo no qual odiar parece ser a forma de salvação, além daquilo que, na sua concepção, o distingue dos outros: “[...] agora o ódio, sim, eu não queria perdê-lo. Eu o alimentava todo o dia, da melhor forma possível. Fora o meu ódio, eu era um ser repugnante que nem aqueles caras que eu odiava” (MELO, 1995, p. 211). Este comentário de Máiquel, que nada parece ter 
de complexo, apresenta-se como uma contradição no contexto da obra. Melo parece querer evidenciar, através destes detalhes linguísticos, que os homens podem separar-se pelas estruturas sociais criadas por eles próprios, mas que, na essência, nos sentimentos, na sua condição de seres humanos, é impossível diferenciá-los.

Quando pensamos que "the self is mirrored in our relations with others" (MIALL, 1989, p. 18), apercebemo-nos que não podemos olhar para Máiquel como um ser/personagem isolado. Ele é um produto daquele meio, de uma estrutura montada para o colocar entre muros. O seu ódio advém de um conjunto de situações e relações que o justificam. A sua desordem interior reflecte o caos da sociedade em que está inserido. Os seus códigos éticos regulam-se pelos da sociedade (ou pela sua falta). Ele é o espelho daquilo que Ariel Dorfman assume como a situação do homem latino-americano:

[...] la necesidad ineludible de una catarsis cotidiana, tomando en cuenta la específica situación del hombre en América, desgarrado por sistemas de valores que le exigen diferentes reacciones, que lo desorientan y enriquecen sus decisiones. La civilización y la barbárie; lo racional y lo irracional; el desarrollo cultural de Occidente, de onde en parte provenimos, y nuestro subdesarrolo económico y social; lo español y la tradición negróideindígena; la ciudad y la naturaleza; el enfrentamiento com el imperialismo y la falta de médios materiales para esta lucha; la división entre intelectuales y pueblo, todo esto, agregado a la complejidad confusa del mundo moderno y la crisis de la cual participamos, hace más angustiosa y difícil la claridad en nuestro continente (DORFMAN, 1970, p. 15).

Décadas mais tarde, em um estudo intitulado "A Pobreza numa Perspectiva de Gênero: reflexões no contexto latino-americano", Lorena da Silva Lopes e Renata Custodio de Azevedo afirmam que,

O surgimento e o aprofundamento do modelo neoliberal de Estado na América Latina trouxeram em seu bojo mudanças significativas nos âmbitos político, econômico, cultural e social. Tais mudanças contribuíram negativamente sobre o setor social, aumentando as desigualdades entre ricos e pobres, o desemprego, os níveis de subemprego e violência, enfim, agravando o fenômeno da pobreza (LOPES e AZEVEDO, 2005, p. 7).

Patrícia Melo apresenta-nos um personagem que estabelece uma ponte com a realidade da vivência da sociedade periférica na linha de Bertold Brecht, que sustém que o autor deve tentar levar o leitor a tomar consciência das situações sociais. Melo consegue, deste modo, abalar no leitor as suas convicções dogmáticas, entre as concepções de certo e errado, de ético 
e desumano, mostrando como a literatura pode ser subversiva na sua forma de representar as complexidades da vida humana.

\section{Ela odeia}

Érica é uma das personagens femininas do romance e aquela que, em alguns momentos, assume o controlo da narração. Depois de Máiquel ter matado seu namorado Suel, Érica coloca-se numa posição de dependência de Máiquel. De acordo com Lúcia Osana Zolin, é Érica que,

[...] como uma locomotiva, na avaliação dele, deixa marcas profundas por onde passa, atropelando tudo, sabedora que é do rumo que deseja imprimir a vida. Sua construção se pauta bem nos moldes dos tempos atuais, em que as mulheres, inclusive aquelas das classes mais populares, podem fazer valer os seus desejos, não se deixando enredar nas teias de ideologias que as submetem e fazem sucumbir-lhes a vontade. Érica sequer pondera a possibilidade de se manter ao lado de Máiquel depois que se dá conta dos valores que regem o seu comportamento. Parece que ela vai, paulatinamente, desvendando o parceiro. E se, num momento inicial, ela tenta desnudar-lhe a objetificação a que a sociedade de classes o está submetendo, num momento posterior, não tendo conseguido abrir-lhe os horizontes, ela se afasta em defesa de seus valores (ZOLIN, 2006, p. 148-9).

Sabemos que na narrativa é Érica, em oposição a Cledir, quem representa um crescente poder do feminino na sociedade atual. No entanto, o que me chama a atenção aqui é a própria subjectividade desta personagem. Érica, tal como Máiquel, sofre as consequências da estrutura social em que se insere. Ariel Dorfman afirma o seguinte, em relação à violência: "Sobrevivir. La violência es el modo habitual de defender-se, el método que está más a mano, el más fácil, a veces el único, para que a uno no lo maten" (DORFMAN, 1970, p. 11). Para que possa sobreviver numa sociedade que a deixou desamparada depois da morte do namorado, Érica não tem outra escolha senão proteger-se através da violência personificada em Máiquel. É interessante verificar como através de uma acção - a morte do seu namorado, a única pessoa que mantinha nela a pureza dos sentimentos - Érica se transforma em uma personagem revoltada, potencializando seu ódio: "Você transformou o meu coração num monte de pedra" (MELO, 1995, p. 46). As suas mudanças repentinas de humor são indicativas de uma personagem com dificuldade de gerir interiormente as repercussões do mundo exterior. Melhor ainda, talvez, a sua interioridade caótica reflecte a desordem do mundo exterior. Para Érica, torna-se quase impossível distinguir entre amor e ódio, sendo que a forma 
de expressar amor é feita através do seu oposto, uma vez que o ódio lhe possibilita uma proteção para o sofrimento. O bilhete que deixa a Máiquel é demonstrativo de tal fato:

Você sabe, eu te odeio.

Vou passar uns dias na casa de minha prima, no Paraná.

Um murro na cara, Érica (MELO, 1995, p. 47).

Érica representa a libertação da mulher, no entanto, representa mais do que isso. Ela retrata igualmente o sofrimento da mulher de classe mais baixa e a dificuldade de sobreviver na falta do elemento masculino. No entanto, Érica traduz ainda uma consciência profunda das relações entre diferentes classes sociais e do poder associado às elites, além da forma como estas oprimem, tanto homens como mulheres, quando afirma:

Escute, Máiquel, deixa eu falar: o presidente de Moçambique estava com uma doença terrível, ele foi a todos os médicos importantes do mundo, na França, na Alemanha, os especialistas diziam sempre a mesma coisa, não sabemos qual é o seu mal [...] a doença dele era ódio, ódio é a mesma coisa que câncer, leucemia, mata (MELO, 1995, p. 169).

A personagem feminina mais esclarecida aponta-nos para o que há de mais negativo no ser humano e esclarece-nos sobre o fato de aqueles que detêm mais poder serem os responsáveis pela propagação de ódio, de desigualdades, de desrespeito pela condição humana, de violência, e pela transformação do humano em desumano:

[...] e agora, olha o que você está fazendo, você é outro, você não está vendo o que esses caras estão fazendo com você, o que este apartamento está fazendo com você, o que este terno está fazendo com você, você mudou, você gostava de sair por aí comigo, gostava de se divertir, de dar risada [...] há um dobermann correndo nas tuas veias, cacos de vidro no teu sangue, há outras coisas também, grades, muros, arame farpado, tudo isso não te deixa dormir [...] (MELO, 1995, p. 70).

Como Érica refere um pouco mais abaixo: "você nem sabe o que é poesia" (MELO, 1995, p. 70). Alerta, deste modo, para o valor da arte em geral, e da literatura em particular, como catarse, ou seja, como antítese da vida prática, dos problemas do quotidiano em que a sobrevivência não deixa lugar para reflexões abstractas, além da sua capacidade de intervenção e criação de um mundo mais humano.

\section{Ele odeia/ eles odeiam}


Martha Nussbaum afirma, em Poetic justice, o seguinte:

[...] novel is a morally controversial form, expressing in its very shape and style, in its modes of interaction with its readers, a normative sense of life. It tells its readers to notice this and not this, to be active in these and not those ways. It leads them into certain postures of the mind and heart and not others (NUSSBAUM, 1995, p. 2).

$\mathrm{O}$ argumento de Nussbaum, neste livro, reincide sobre a forma como a literatura participa da vida real, tendo o potencial de trazer uma contribuição importante à vida pública. Este aspecto, infelizmente, tem se perdido, hoje, havendo cada vez mais uma separação de campos em que a literatura é identificada com um aspecto mais emotivo, pessoal e subjectivo da vida pessoal, sendo incapaz de iluminar, quando estão em causa questões nacionais ou desigualdades sociais, por exemplo. No entanto, Nussbaum argumenta exactamente que "literary forms have a unique contribution to make" (NUSSBAUM, 1995, p. 3) na vida pública. Através do interesse geral do romance em aspectos ordinários da vida, o leitor é convidado a refletir que a sua experiência leitora tem pontos comuns e outros dessemelhantes em relação à experiência dos personagens, o que o leva a avaliar e equilibrar os seus julgamentos morais e políticos com os insights oferecidos pela leitura. Assim sendo, Nussbaum defende que "reading can lead us to alter some of our standing judgments" (NUSSBAUM, 1995, p. 10).

Através do dr. Carvalho, Melo leva o leitor a confrontar-se com esse aspecto da literatura, iluminadora da esfera pública. Este personagem é representativo de uma elite cujos objectivos não passam da mera intenção de extorquir do seu ambiente uma camada da sociedade que é vista por si como ameaçadora do bem-estar. Ele faz parte da elite criadora das regras do jogo, cuja condição econômica lhe permite contratar para matar e sair impune. $\mathrm{O}$ ódio que sente em relação aos de condição inferior demonstra a que ponto o ser humano pode ser cruel com o seu semelhante no simples egoísmo de conservar para si os privilégios: “[...] os jornais, ele disse, os jornais conseguem deixar o nosso ódio bem fresquinho, se o eu ódio está assim, meio anémico, é só você passar os olhos no jornal, essa é a verdade" (MELO, 1995, p. 188).

Através deste personagem, Patrícia Melo coloca o leitor perante as máscaras sociais, em confronto com uma elite que vive de aparências, em que o lado material da vida é sobreposto ao lado humano, emotivo e espiritual. Os exemplos abaixo são bastante 
exemplificativos da desconstrução de uma visão da elite como a classe representativa da ética e dos bons costumes:

Dentistas, comerciantes, advogados, industriais, funcionários, médicos e executivos, esses caras não gostam de foder. Principalmente os jovens. Primeiro eles têm de comprar cedê, computador, assinar contratos, carro do ano, ter filhos, impressionar o vizinho, arruinar o casamento, lavar o carro, maltratar a empregada, se sobrar tempo, eles fodem (MELO, 1995, p. 108). O problema não era eu ter vendido pó para a filha dele. O problema não era o fato de a filha ser cocainómana. O problema era a filha dele ter contado para mim que ia ser internada, era isso que ele não podia tolerar, as pessoas saberem. Cheirar pó, tudo bem. Dar o cu, tudo bem. Roubar do sócio, matar crianças, tudo bem. O problema, esses caras sempre pensam assim, o problema é quando os canos estouram. A água suja que escorre. O que é que os vizinhos vão pensar? Esses caras vivem para os vizinhos (MELO, 1995, p. 190).

Através do dr. Carvalho, de seus amigos e de Santana, o policial corrupto, o leitor percebe que as possíveis regras existentes na sociedade servem apenas alguns, que a camada mais alta da sociedade forma um muro que é quase impossível ultrapassar:

Eu venci, ele falou, eu tenho um carro bacana, eu tenho dinheiro, ninguém suporta isso, um preto com dinheiro num carro bacana, um preto entrando num restaurante, um preto numa boa dando risada por aí, eles não toleram, ficam doidos de ódio, a realidade é essa [... ] (MELO, 1995, p. 152).

O ódio, o medo que do dr. Carvalho por ser incomodado representa um modo de vida em que se torna mais fácil e confortável mandar matar aqueles que são considerados o "podre" social, do que criar estruturas que os integrem e lhes deem iguais oportunidades de acesso à educação, à cultura, aos meios econômicos, ao simples trabalho. Esta personagem põe em causa o código ético de que se diz representante e obriga-nos a colocar a questão sobre quem é o verdadeiro matador no romance, aquele que exerce literalmente o ato ou aquele que o manda executar?

Em uma leitura cerrada de Máiquel e do dr. Carvalho, pode observar-se que o primeiro é dotado de uma consciência, de complexidade interior, de paixões, de contradições que o tornam humano e realista. No segundo caso, podemos fazer uso das palavras de Deonísio da Silva, quando este afirma que

A 'gente fina e nobre', ao contrário, que não tem carência de nada, vive invariavelmente atribulada, cheia de angústias diversas, sem amor, sem paixões avassaladoras como aquelas que tomam conta das periferias sócio- 
econômicas. São proprietários, moram em mansões belíssimas, vestem-se de ouro e púrpura, estudam nas melhores escolas, comem nos mais finos restaurantes, bebem o que de melhor o país importa e, entretanto, estão sempre perdidos num grande vazio (SILVA, 1983, p. 109).

É o vazio interior que provoca no dr. Carvalho e seus amigos o ódio, que os torna objectos da sua própria ganância.

Regressando a Martha Nussbaum, esta afirma que:

Literary works that promote identification and emotional reaction cut through those self-protective stratagems, requiring us to see and to respond to many things that may be difficult to confront - and they make this process palatable by giving us pleasure in the very act of confrontation (NUSSBAUM, 1995, p. 6).

É exactamente este tipo de identificação que Patrícia Melo consegue com o dr. Carvalho. O dentista coloca o leitor em confronto com as suas próprias ações perante a sociedade e com o fato de ele próprio, possivelmente, se identificar em certos aspectos com o dr. Carvalho. É, talvez, essa uma das razões de ser um livro difícil de ler até ao fim, uma vez que o leitor tem de responder a certas questões que são difíceis de serem confrontadas.

\section{Nós odiamos (conclusão)}

Hans Robert Jauss, em um artigo a propósito do problema da identificação entre herói e espectador/leitor, relação esta que tem sido desacreditada no nível da estética contemporânea e, igualmente, na prática da literatura moderna e da arte, afirma que existe "the possibility of aesthetic enjoyment even in relation to affections which at first glance do not seem 'enjoyable,' as for example horror, repugnance or shock” (JAUSS, 1974, p. 286). Neste sentido, o prazer do leitor em termos de faculdades afetadas liga-se ao da identificação com as acções e sofrimentos dos personagens. Ao referir-se ao prazer estético de identificação traçado por Sigmund Freud, Jauss alega que:

[...] aesthetic identification can transform others' experience, which one would hardly have thought oneself capable of, into a source of pleasure, because it presupposes illusion: 'that is, the mitigation of suffering by the certainty, first, that it is someone else who is acting and suffering on the stage, and second, that it is all a game, which cannot endanger one's personal security (JAUSS, 1974, p. 287). 
Neste romance de Patrícia Melo, encontramos os dois níveis: por um lado, a experiência vivida por Máiquel representa prazer estético, no sentido em que a linguagem nos "agarra" e porque, como sujeitos, apreciamos o puro funcionamento das nossas faculdades ao serem afetadas pelos objectos. Por outro lado, essa identificação estética proporciona prazer, uma vez que, como acima referido, o leitor sabe que se trata de uma ilusão, que apesar de se identificar com o problema de Máiquel, essa identificação não poderá derrubar os muros construídos à volta da sua estabilidade material e social. No entanto, parece-me que o romance de Patrícia joga com estas noções e tenta desequilibrá-las. Ao retratar um problema contemporâneo - o da marginalização da população periférica, que embora viva em contato com a população urbana oficial, dela se afasta por barreiras invisíveis criadas pela elite. Fazendo uso de um narrador que desmascara abertamente o funcionamento (ou a falta dele) das instituições sociais, a autora cria no leitor a sensação de participação, conivência e compactuação na desigualdade. É quase impossível o leitor sentir que está a viver um mundo de ilusão quando segue o Matador. Ele nunca se furta de perturbar a consciência do leitor, de desestabilizar os seus muros e de o fazer encarar de frente problemas cujo silêncio, ou o fechar de olhos perante eles, faz com que cada membro da sociedade se sinta culpado e responsável. Máiquel representa uma realidade demasiado incômoda para ser encarada e discutida. Como pode o narrador sentir tanto ódio? Como pode ele odiar uma classe social que se comporta dentro da "norma"? - poderão perguntar-se incomodados aqueles que se consideram dentro dessa norma. No entanto, Máiquel coloca o mundo às avessas ao fazer o leitor aperceber-se que compartilha com o narrador algumas características. Tal como Máiquel odeia a sociedade representada pelo dr. Carvalho, o leitor (provavelmente inserido no lado do dr. Carvalho) igualmente odeia a sociedade de Máiquel. No entanto, mantém a aparência que se esconde por detrás da conduta normalizadora da sociedade.

Na verdade, cada um de nós acaba por fazer o que o dr. Carvalho, Virgínia e todos os “do lado de lá” fizeram com Máiquel:

E a professorinha? Virgínia, eu pensava nela. Ela tinha gostado de mim. Ficou impressionada comigo, a medalha. Eu tinha ficado de telefonar. Podia ser uma boa. Resolvi ligar. Ela não teve o menor cuidado, manda dizer que eu não estou, ela falou, e falou bem perto do bocal, eu ouvi tudo. Ela não está, disse a empregada. Menos uma. Aos poucos todos eles iam me abandonando (MELO, 1995, p. 111). 
O matador é um livro que nos coloca perante as desigualdades sociais e em confronto com o nosso papel em relação ao "outro" e as oportunidades de escolha em sociedades que a limitam. Coloca-nos ainda na presença de uma sociedade aparentemente sem ética, cujo próprio aparelho de Estado não assegura a convivência das diferenças, o que resulta em caos e indivíduos perdidos na busca de algo que proporcione ordem e estabilidade. É o caso de Máiquel. De acordo com David Miall (1989, p. 12),

In the modernist text, as well as (perhaps) many earlier ones, there is an overthrowing of our 'frames,' or at least a bracketing or suspension of them. It is our experience of this process which, according to Iser, impels a reshaping of the self.

Máiquel obriga o leitor, a isso mesmo, a colocar em causa o seu quadro de valores e ideias pré-concebidas e a reformular-se como ser humano, encarando o fato de ser imanente a qualquer ser humano a violência, o ódio, o egoísmo. Em oposição a outros meios que nos comunicam a violência, o romance de Patrícia Melo, como outros do mesmo género, representa uma forma de literatura que resiste a compactuar com o sistema. De acordo com Ronaldo Lima Lins (1990, p. 48),

É verdade que, considerada como um todo, a literatura faz bem mais do que
refletir sobre o problema da consciência ou retratar a tragédia de um homem
incapaz de ajustar-se. Se assim fizesse estaria, aliás, limitando o espaço de
sua atuação e omitindo elementos importantes. A representação da realidade
no romance do século XX, implica numa totalidade de percepção à qual não
escapa a comunicação em si, na forma como se dá em nossos dias, e a
violência do impasse no qual se situa a inteligência em nossa época. É desta
maneira que, num romance fragmentado em sua composição formal, como é
fragmentado o homem das ruas, seja ele um banqueiro ou um assaltante,
existe uma constatação, uma crítica e a possibilidade de uma saída, ainda
que, em certos casos, semelhante saída se mostre tão ténue quanto a
realidade do trabalho criativo.

A literatura em geral, e o romance de Patrícia Melo, em particular, oferece-nos uma visão mais complexa da vida humana e da realidade social no Brasil. O romance não parece oferecer saída para os personagens que vivem "do lado de lá", mas proporciona como reflexão a possibilidade do leitor, como cidadão preocupado e conscientizado, pensar na forma como participa no e para o mundo das desigualdades sociais.

\section{Referências bibliográficas:}


DORFMAN, Daniel. Imaginación y violencia en America. Chile: Editorial Universitária, 1970.

JAUSS, Hans Robert. Levels of identification of Hero and Audience. New Literary History, v. 5, n. 2, 1974, p. 283-317.

JÚNIOR, Benilton Bezerra. Pobreza, agressividade e consumo: três observações sobre a violência no Brasil. In: FEGHALI, Jandira; MENDES, Cândido; LEMGRUBER, Julita (Orgs.). Reflexões sobre a violência urbana, (in) segurança e (des) esperanças. Rio de Janeiro: Mauad, 2006, p. 43-59.

LINS, Ronaldo Lima. Violência e literatura. Rio de Janeiro: Tempo Brasileiro, 1990.

LOPES, Lorena da Silva; AZEVEDO, Renata Custodio de. A pobreza numa perspectiva de gênero: reflexões no contexto latino-americano. II Jornada Internacional de Políticas Públicas, Mundialização e Estados Nacionais, São Luiz, UFMA, agosto de 2005. http://www.joinpp.ufma.br/jornadas/joinppII/pagina_PGPP/Trabalhos2/Lorena_da_Silva_Lop es_Renata\%20Custodio\%20de\%20Azevedo238.pdf.

MELO, Patrícia. O matador. Porto: Campo das Letras, 1995.

MIALL, David. Text and affect: a model of story understanding. Re-reading the short story. In: HANSON, Clare (Ed.). New York: St. Martin's Press, 1989, p. 10-21.

NUSSBAUM, Martha C. Reading for life. Love's knowledge: essays on philosophy and literature. New York; Oxford: Oxford UP, 1990, p. 230-244.

Poetic justice: the literary imagination and public life. Boston: Beacon Press, 1995.

RICOEUR, Paul. Life: a story in search of a narrator. Facts and values. DOESER, M. C. (Ed.); KRAAY, J. N. Dordrecht: Martinus Nijhoff Publishers, 1986.

Silva, Deonísio da. O caso Rubem Fonseca: violência e erotismo em Feliz Ano Novo. São Paulo: Alfa-Omega, 1983.

ZOLIN, Lúcia Osana. Alguns Apontamentos sobre gênero e representação na ficção de Patrícia Melo. Línguas e Letras, v. 7, n.13, 2006, p. 145-161.

The conjugation of the verb to hate in $O$ matador, by Patrícia Melo

Abstract: The main purpose of this article is to problematize through the analysis of Patrícia Melo's $O$ matador the already old debate about the role of ethics in literary criticism. Belonging to a new generation of Brazilian writers, Patrícia Melo brings to her literary work 
issues that destabilize dichotomous views about life and human beings, rekindling the flame on the problematic of the role of literature and art in contemporary society.

Key words: Ethics. Life. Art. Literature. Dichotomy. 